\title{
EXOCRINE AND ENDOCRINE PANCREATIC INSUFFICIENCY IN DEVELOPMENT OF ATHEROSCLEROSIS
}

\author{
Pylov D., Zhuravlyova L. \\ Kharkiv National Medical University, Kharkiv, Ukraine \\ https://doi.org/10.35339/ic.7.4.159-163
}

\begin{abstract}
Objective: To evaluate the effect of chronic pancreatitis (CP) and exocrine insufficiency of the pancreas on the carotid intima media thickness (cIMT) in patients with type 2 diabetes mellitus (DM-2). Materials and methods: 91 patients were examined, they were divided into groups: group 1 - patients with $\mathrm{DM}-2(\mathrm{n}=31)$, group $2-\mathrm{DM}-2$ combined with $\mathrm{CP}(\mathrm{n}=60)$. Fasting plasma glucose (FPG), HbAlc, immunoreactive insulin (IRI), HOMA-IR index, C-reactive protein (CRP), serum $\alpha$-amylase and fecal-1 elastase (FE-1) were assessed. In order to assess the thickness of the cIMT, ultrasonography of the common carotid artery was performed. The control group of healthy volunteers was representative by age and sex. Results. In groups 1 and 2 , the average value of cIMT was $(1.02 \pm 0.1$ vs. $1.21 \pm 0.15) \mathrm{mm}$. The parameters of DM-2 management in groups 1 and 2 were (FPG $8.18 \pm 0.92$ vs. $8.57 \pm$ 1.2) $\mathrm{mmol} / \mathrm{l}$; HbAlc ( $7.23 \pm 0.21$ vs. $7.49 \pm 0.36) \%$; IRI $(20.31 \pm 0.9$ vs. $22.53 \pm 1.2) \mu \mathrm{IU} / \mathrm{ml}$; HOMA-IR ( $6.55 \pm 1.5$ vs. $8.38 \pm 2.2)$; PSA ( $1.3 \pm 0.12$ vs. $6.77 \pm 0.31)$. HOMA-IR correlated with: CRP ( $\mathrm{r}=0.43, \mathrm{p}<0.05$ in group $1 ; \mathrm{r}=0.61, \mathrm{p}<0.05$ in group 2); FE-1 $(\mathrm{r}=-0.55$, $\mathrm{p}<0.05$ of group 2); and cIMT ( $\mathrm{r}=0.42, \mathrm{p}<0.05$ in group 1 ; $\mathrm{r}=0.53, \mathrm{p}<0.05$ in group 2). IRI have relationship with FE-1 ( $\mathrm{r}=0.41, \mathrm{p}<0.05$ in group $1 ; \mathrm{r}=-0.3, \mathrm{p}<0.05$ in group 2); CRP $(r=0.42, p<0.05$ in group $1 ; \mathrm{r}=-0.28, \mathrm{p}<0.05$ in group 2$)$; $\mathrm{HbA} 1 \mathrm{c}$ had close relationships with cIMT $(\mathrm{r}=0.38, \mathrm{p}<0.05$ in group $1 ; \mathrm{r}=0.51, \mathrm{p}<0.05$ in group 2$)$; the relationship between cIMT and CRP was related in group $2(\mathrm{r}=0.39, \mathrm{p}<0.05)$; with $\alpha$-amylase $(\mathrm{r}=0.2$, $\mathrm{p}<0.01$ group 2). There was no significant relationship between cIMT and FE-1 in the study. Conclusions: the obtained data allow concluding that hyperinsulinemia and insulin resistance have a direct atherogenic effect on the walls of the blood vessels. It is established that the accession of the inflammatory process leads to increasing development of atherosclerotic lesions of the vessel, at the same time, the presence of exocrine dysfunction of the pancreas does not have a significant direct effect on the cIMT.

Keywords: chronic pancreatitis type 2 diabetes mellitus, atherosclerosis, carotid intima media thickness.
\end{abstract}

\section{Introduction}

Modern medicine data show that the pancreas due to a combination of incretory and excretory functions is involved in all physiological processes [1]. Therefore, any disturbance in pancreas function, like chronic pancreatitis (CP) or type 2 diabetes mellitus (DM-2), leads to disturbance of stability of the internal environment of the organism. [2]. The problem of combined pathology DM-2 and CP, which, according to statistic data, is diagnosed in $28-36 \%$ of patients with DM-2,

\footnotetext{
Corresponding Author:

Daniel Pylov, MD, PhD student of the Department of Internal Medicine \#3 and endocrinology, Kharkiv National Medical University, Kharkiv, Ukraine. E-mail: danielpylov@gmail.com
}

has attracted attention of scientists [3]. In the study [4], main markers of presence DM-2 were highlighted, as well as factors of formation CP in DM-2 patients, the influence of excess body weight, obesity, hyperglycemia and hyperlipidemia, development of hyperinsulinemia and insulin resistance (IR) was recognized as crucial. CP is the result of long-term chronic inflammation and fibrosis of the pancreas [5]. Parallel with CP inflammatory processes the processes of atherogenesis take place in patients with DM-2. The pancreas is an organ that undergoes structural and functional changes due to atherosclerotic damage. Due to vascular lesions of atherosclerotic origin in the islets of the pancreas, blood flow is reduced and hypoxia is observed with a consistent 
functional decrease in beta-cells. The islets undergo structural changes, accompanied by the appearance of hyalinosis and loss of beta-cells. According to D. Rosso et al. [6], 87.5\% of patients with DM-2 have thickening and stenosis of the arterioles of the pancreas, and in $50 \%-$ lesions of the islets of Langerhans. Therefore, development of CP in patients with DM-2 is just a question of time. The aged-related pancreatic changes are considered to be related to atherosclerosis (of small vessels) by few studies [7]. Researchers drew attention to the more frequent lesions of the cardiovascular system in patients with combine DM-2 and CP rather than isolated disease and suggested the possibility of promoting development of such lesions by CP [8]. Against a background of various disorders of the metabolic process, atherogenesis occurs not only locally in the vessels of the pancreas, but also in other vessels. That is why some authors have linked cardiovascular events (CVE) to exocrine pancreatic insufficiency [9]. Standard risk factors associated with the development of CVE include age, high blood pressure, higher body mass index (BMI), and smoking which stimulate development of atherogenesis as well [10]. Atherosclerosis is a multifactorial disease involving the interplay of many factors such as hyperlipidemic and hyperglycemic states, inflammation, however, any one of these alone is insufficient to produce an atherosclerotic lesion that is why people with combined diseases more likely to develop atherosclerosis.

Carotid intima-media thickness (cIMT) is a diagnostic marker of subclinical atherosclerosis in the population [11]. According to numerous studies, cIMT associated with prediction of cardiovascular risk in population [12-14]. cIMT has been correlated with CVE [15] and mortality among people with chronic disease and DM [16]. In individuals with DM-2, CIMT has been reported as a predictor of adverse cardiovascular outcomes in previous longitudinal studies [17-19].

According to statistic data, $75 \%$ of patients with DM-2 die from the causes associated with atherosclerosis, namely, coronary heart disease, ischemic stroke, heart failure [20,21]. Researchers note that the atherosclerotic vascular lesions in people with DM-2 develop 7-10 years earlier than in people without DM [22]. Thus, the frequency of CVE in patients with DM-2 is associated with atherosclerosis development and the inability to compensate the changes caused by it $[23,24]$.

The risk of CVE in patients with combined DM-2 and CP is many times higher, because relationship between insulin resistance, hyperglycemia, inflammation and development of atherosclerosis is very complex and covers many factors. A meta-analysis showed that an increase of cIMT by $0.13 \mathrm{~mm}$ is associated with increasing risk of CVE by almost $40 \%$ in patients with DM-2 [25].

In the available literature, we have not found the data about relationship between exocrine function of the pancreas and the development of atherosclerosis in patients with DM-2 and CP, which was the reason for this study.

\section{Purpose, subjects and methods:}

2.1. The purpose To evaluate the effect of exocrine insufficiency of the pancreas and parameters of carbohydrate metabolism on the carotid intima media thickness in patients with diabetes mellitus type 2 and chronic pancreatitis.

\subsection{Subjects \& Methods}

The study involved 91 patients with DM-2 who were divided into groups: group lincluded the patients with DM-2 $(\mathrm{n}=31)$; group 2 - patients with DM-2 and chronic pancreatitis $(n=60)$. The diagnosis of DM-2 was established based on the local guidelines (based on the recommendations of the European Association for Diabetes 2017). The diagnosis of CP was established based on local guidelines and recommendations of the Association of European Gastroenterology (UEG) for the diagnosis and management of CP 2017. The control group included 20 age-matched healthy individuals (10 men). All patients were informed about the study procedure and signed a written consent for participation.

In the study, the parameters of carbohydrate metabolism compensation were determined: fasting plasma glucose level (FPGL) - glucose oxidant method, glycosylated hemoglobin (HbAlc) by immunoturbidimetric method, immunoreactive insulin (IRI) which was determined by the enzymelinked immunosorbent assay. The HOMA-IR index was calculated using the formula $-($ FPGL*IRI $) / 22$. The functional state of the pancreas was determined by the content of $\alpha$-amylase in the blood plasma and fecal elastase-1 (FE-1). The level of quantitative $\mathrm{C}$-reactive protein (CRP) was assessed. The body mass index was calculated according to the formula Kettle - body weight $(\mathrm{kg}) /$ height $\left(\mathrm{m}^{2}\right)$.

cIMT was assessed using ultrasonography (SIEMENS ACUSON S3000) in the proximal and distal parts of the carotid artery. cIMT was measured in B-mode, in the longitudinal section of the artery $1-1.5 \mathrm{~cm}$ proximal to the bifurcation along the posterior wall of the artery. The value of the CIMT of the carotid artery was measured three times on each side, and then the average 
value for the right and left carotid artery was calculated on the basis of the obtained data from the three-time measurement. The atherosclerotic plague was considered to be a focal structure that protrudes into the lumen of the vessel by $0.5 \mathrm{~mm}$ or $50 \%$ more than the value of the cIMT of the adjacent areas of the artery, or an increase of cIMT more than $1.3 \mathrm{~mm}$. The thickness norm of cIMT corresponded to the recommendations of the European Society of Hypertension (ESH) and the European Society of Cardiology (ESC) in 2013 and was $0.9 \mathrm{~mm}$.

The obtained data were processed using the package Statistica Basic Academic 13 for Windows En. Quantitative indicators are given in the form of median (Me) and interquartile range (LQ lower quartile, UQ - upper quartile), as well as in the form of $\mathrm{M} \pm \mathrm{m}$, where $\mathrm{M}$ is the sample mean, $\mathrm{m}$ is the standard deviation. KolmogorovSmirnov criterion was used to verify the compliance of the distribution of quantitative indicators with the normal law. Because the law of distribution of numerical indicators differed from normal, nonparametric statistical methods were used: Kruskal-Wallis test (KWT) and Mann-Whitney U-test (MWT). To determine the existence of functional relationships between the parameters, the nonparametric rank correlation coefficients of Spearman (r) was calculated, which was considered statistically significant at $\mathrm{p}<0.05$.

\section{Conflict of interests}

The authors of the article declare no conflict of interest.

\section{Results \& discussion}

The main results of the study are presented in the Table. The studied indicators significantly depended on the group (CCU, $\mathrm{p}<0,05$ ).

The obtained data of carbohydrate metabolism suggest that accession of chronic pancreatitis leads to more poor management of DM-2. FPGL in group 1 is higher than in group $2(8.18 \pm 0.92$ vs. $8.57 \pm 1.2) \mathrm{mmol} / \mathrm{l}$; management of DM not only in short period of time is poor, but also during a longer period of time according to $\mathrm{HbAl}$ c level $(7.23 \pm 0.21$ vs. $7.49 \pm 0.36) \%$; IRI $(20.31 \pm 0.9$ vs. $22.53 \pm 1.2) \mu \mathrm{IU} / \mathrm{ml}$; HOMA-IR (6.55 \pm 1.5 vs. 8.38 $\pm 2.2) \mu \mathrm{IU} / \mathrm{ml} * \mathrm{mmol} / \mathrm{l}$. Poor management of DM-2 in group 2 can be explained by the fact of loss of glucagon response to hypoglycemia and disturbance of carbohydrate absorption. The signs of inflammation were obtained in group 2. In comparison to group1, group 2 in our study had higher level of CRP $(1.3 \pm 0.12$ vs. $6.77 \pm 0.31)$. The signs of pancreas exocrine disturbance were present only in group 2 : $\alpha$-amylase $29.1(26.39-32)$ vs. 32.64 (29.15-35.40) g/g*L; and FE - 1 - 292.4 (271.1-302.27) vs. $137.51(131.55-142.2) \mu \mathrm{g} / \mathrm{g}$. These results confirmed the presence of exocrine pancreatic dysfunction in patients of group 2. In groups 1 and 2 the average value of cIMT was

Indicators of carbohydrate metabolism, inflammation, functional state of the pancreas and the level of adipocytokines and CMI ICA in the examined patients (Me (LQ-UQ))

\begin{tabular}{|c|c|c|c|}
\hline Parameter & $\begin{array}{c}\text { Group 1: DM } \\
(n=31)\end{array}$ & $\begin{array}{c}\text { Group 2: CP + DM-2 } \\
(n=60)\end{array}$ & $\begin{array}{c}\text { Control group } \\
(n=20)\end{array}$ \\
\hline $\begin{array}{l}\text { Duration of DM-2 } \\
\text { (years) }\end{array}$ & $9.02 \pm 1.85$ & $9.61 \pm 2.13$ & - \\
\hline BMI $\left(\mathrm{kg} / \mathrm{m}^{2}\right)$ & 28.18 [24-33] & 30.66 [28-34] & 25.68 [21-23] \\
\hline IRI $(\mu \mathrm{IU} / \mathrm{mL})$ & $\begin{array}{c}20.31 \\
\left.(10.96-25.3)^{\star}\right)\end{array}$ & $\begin{array}{c}22.53 \\
\left.(13.95-30.45)^{*}\right)\end{array}$ & $\begin{array}{c}11.07 \\
(8.61-13.46) \\
\end{array}$ \\
\hline $\begin{array}{l}\text { FPGL } \\
(\mathrm{mmol} / \mathrm{L})\end{array}$ & $\begin{array}{c}8.18 \\
\left.(6.40-9.70)^{*}\right)\end{array}$ & $\begin{array}{c}8.57 \\
\left.(6.5-10.1)^{*}\right) \\
\end{array}$ & $\begin{array}{c}4.75 \\
(4.5-5.0)\end{array}$ \\
\hline $\begin{array}{l}\mathrm{HbA1c} \\
(\%)\end{array}$ & $\begin{array}{c}7.23 \\
\left.\left.(6.58-7.89)^{*}\right)^{\star *}\right)\end{array}$ & $\begin{array}{c}7.49 \\
\left.(6.12-8.72)^{*}\right)\end{array}$ & $\begin{array}{c}5.39 \\
(5.32-5.46) \\
\end{array}$ \\
\hline $\begin{array}{l}\text { HOMA-IR index } \\
(\mu \mathrm{IU} / \mathrm{mL})^{*}(\mathrm{mmol} / \mathrm{L})\end{array}$ & $\begin{array}{c}6.55 \\
\left.\left.(3.90-8.99)^{*}\right)^{* \star *}\right)\end{array}$ & $\begin{array}{c}8.38 \\
\left.(4.69-10.71)^{*}\right)\end{array}$ & $\begin{array}{c}2.39 \\
(1.83-2.96)\end{array}$ \\
\hline $\begin{array}{l}\text { CRP } \\
(\mathrm{mg} / \mathrm{L})\end{array}$ & $\begin{array}{c}1.33 \\
\left.\left.(0.0-2.0)^{*}\right)^{* * *}\right)\end{array}$ & $\begin{array}{c}6.77 \\
\left.(1.19-11.92)^{*}\right)\end{array}$ & $\begin{array}{c}0.12 \\
(0.0-0.23)\end{array}$ \\
\hline $\begin{array}{l}\alpha \text {-amylase } \\
\left(g / g^{*} L\right)\end{array}$ & $\begin{array}{c}29.1 \\
\left.\left.(26.39-32)^{*}\right)^{\star \star *}\right)\end{array}$ & $\begin{array}{c}32.64 \\
\left.(29.15-35.40)^{\star}\right)\end{array}$ & $\begin{array}{c}24.71 \\
(19.7-28.6)\end{array}$ \\
\hline $\begin{array}{l}\text { Elastase-1 } \\
(\mu \mathrm{g} / \mathrm{g})\end{array}$ & $\begin{array}{c}292.4 \\
\left.\left.(271.1-302.27)^{*}\right)^{* \star *}\right)\end{array}$ & $\begin{array}{c}137.51 \\
\left.(131.55-142.2)^{*}\right)\end{array}$ & $\begin{array}{c}348.96 \\
(289-381)\end{array}$ \\
\hline $\begin{array}{l}\mathrm{cIMT} \\
(\mathrm{mm})\end{array}$ & $\begin{array}{c}1.02 \\
(0.75-1.24) \\
\end{array}$ & $\begin{array}{c}1.21 \\
(0.84-1.33) \\
\end{array}$ & $\begin{array}{c}0.71 \\
(0.64-0.81) \\
\end{array}$ \\
\hline
\end{tabular}

Note. The difference is statistically significant $(\mathrm{p}<0.05)$ when comparing indicators:

*) - probable when comparing identical parameters in control patients;

***) - probable when comparing identical parameters between the groups 1 and 2 . 
$(1.02 \pm 0.1$ vs. $1.21 \pm 0.15) \mathrm{mm}$ with relatively equal duration of DM-2 $(9.02 \pm 1.85$ vs. $9.61 \pm 2.13)$ in the studied groups.

The correlation relationship between the studied parameters was as follows: HOMA-IR correlated with CRP $(\mathrm{r}=0.43, \mathrm{p}<0.05$ in group 1 ; $\mathrm{r}=0.61, \mathrm{p}<0.05$ in group 2; FE-1 in group 2 $\mathrm{r}=-0.55, \mathrm{p}<0.05$; cIMT in group $1 \mathrm{r}=0.42$, $\mathrm{p}<0.05$; and in group $2 \mathrm{r}=0.53, \mathrm{p}<0.05$. IRI relationship was associated with: FE-1 $\mathrm{r}=0.41$, $\mathrm{p}<0.05$ in group 1 ; and $\mathrm{r}=-0.3, \mathrm{p}<0.05$ in group 2 ; CRP ( $\mathrm{r}=0.42, \mathrm{p}<0.05$ in group $1 ; \mathrm{r}=-0.28$, $\mathrm{p}<0.05$ in group $2 ; \mathrm{HbA} 1 \mathrm{c}$ had close relationships with cIMT $r=0.38, p<0.05$ in group $1 ; r=0.51$, $\mathrm{p}<0.05$ in group 2 , this finding can be explained by the fact that $\mathrm{HbA} 1 \mathrm{c}$ is a marker reflecting the compensation of DM over a long period of time in comparison to FPGL. However, the study conducted by Gomez-Marcos MA et al. [25] showed that HbA1c level did not correspond to carotid atherosclerotic parameters in the overall population without carbohydrate metabolism disturbance. The relationship between cIMT and CRP in our study was reliable in group $2(r=0.39$, $\mathrm{p}<0.05$ ), practically the same results were obtained in the study conducted by Magdalena Boncler et al. [26], where CRP correlated with CVE. In our case this relationship in group where patients have chronic inflammation can be explain in the following way: CRP plays a key role in all phases of chronic inflammation and atherosclerosis as well, CRP have directly influences the progression of atherogenesis: such as complement activation, apoptosis and thrombosis according to Elaine et al. study [27]. In the same time, research by Steyers $\mathrm{CM}$ et al. [28] maintain that chronic inflammation has been found to be associated with accelerated atherosclerosis and increased risk of CVDs.

\section{References}

1. Gubergric NB, Kazjulin AN. (2011) Metabolicheskaja pankreatologija. Doneck: Lebed'; 514 s.

2. Komissarenko IA. (2009) Polimorbidnost' i metabolicheskij sindrom u pozhilyh. Klinicheskaja gerontologija.; 1: 29-38.

3. Piciucchi M, Capurso G. (2015) Exocrine pancreatic insufficiency in diabetic patients: prevalence, mechanisms, and treatment. Int J Endocrino.

4. Pezzilli R, Calculli L. (2014) Pancreatic steatosis: Is it related to either obesity or diabetes mellitus? World J Diabetes; 5: 415-419.

5. Lew D, Afghani E, Pandol S. (2017) Chronic Pancreatitis: Current Status and Challenges for Prevention and Treatment. Dig Dis Sci; 62(7): 1702-1712

6. Rosso D, Carnazzo G, (2001) Atherosclerosis and pancreatic damage. Arch Gerontol Geriatr; 32(2): 95-100.

7. Lohr JM, Panic N, (2018). The ageing pancreas: a systematic review of the evidence and analysis of the consequences. J Intern Med; 283: 446-460 DOI:10.1111/joim.12745

8. Gullo, L, Stella A(1982). Cardiovascular lesions in chronic pancreatitis. Digest Dis Sci. 1982; 27: 716.

9. de la Iglesia D, Vallejo-Senra N, (2018). Pancreatic exocrine insufficiency and cardiovascular risk in patients with chronic pancreatitis: A prospective, longitudinal cohort study. J Gastroenterol Hepatol [Internet]. Available from: https://www.ncbi.nlm.nih.gov/pubmed/30156337/]. 
10. Carpenter M, Sinclair H, (2016). Carotid intima media thickness and its utility as a predictor of cardiovascular disease: a review of evidence. Cardiol Rev.;24:70-75.

11. Liviakis L, Pogue B, Paramsothy P,( 2010). Carotid intima-media thickness for the practicing lipidologist. J Clin Lipidol;4:24-35

12. Polak JF, Pencina MJ, (2011). Carotid-wall intima-media thickness and cardiovascular events. N Engl J Med. 2011;365:213-21. 2.

13. Baldassarre D, Hamsten A (2012). Measurements of carotid intima-media thickness and of interadventitia common carotid diameter improve prediction of cardiovascular events: results of the IMPROVE (carotid intima media thickness [IMT] and IMT-progression as predictors of vascular events in a high risk european population) study. J Am Coll Cardiol.;60:1489-99

14. O'Leary DH, Polak JF, Kronmal RA, et al (1999). Carotid-artery intima and media thickness as a risk factor for myocardial infarction and stroke in older adults. Cardiovascular Health Study Collaborative Research Group. N Engl J Med.;340:14-22

15. Lorenz MW, Markus HS, Bots ML, et al. (2007) Prediction of clinical cardiovascular events with carotid intimamedia thickness: a systematic review and meta-analysis. Circulation.;115:459-467

16. Shoji T, Kawagishi T, Emoto M, et al. (2000) Additive impacts of diabetes and renal failure on carotid atherosclerosis. Atherosclerosis.;153:257-258.

17. Yoshida M, Mita T, Yamamoto R, et al (2012). Combination of the Framingham risk score and carotid intima-media thickness improves the prediction of cardiovascular events in patients with type 2 diabetes. Diabetes Care.;35:178-80. 6.

18. Malik S, Budof MJ, Katz R, et al (2011). Impact of subclinical atherosclerosis on cardiovascular disease events in individuals with metabolic syndrome and diabetes: the multi-ethnic study of atherosclerosis. Diabetes Care.;34:2285-90. 7.

19. Katakami N, Mita T, Gosho M, (2018). Clinical utility of carotid ultrasonography in the prediction of cardiovascular events in patients with diabetes: a combined analysis of data obtained in fve longitudinal studies. J Atheroscler Thromb;25:1053-66

20. Aronson D, Edelman ER (2014). Coronary artery disease and diabetes mellitus. Cardiology Clinics.; 32(3): 439-455.

21. Cecilia C, Wang L, (2016). Atherosclerotic Cardiovascular Disease and Heart Failure in Type 2 Diabetes - Mechanisms, Management, and Clinical Considerations. Circulation; 133(24): 2459-2502

22. Citovs'kij MN. Statistichnij (2017), Klinichnij ta morfologichnij aspekti vplivu cukrovogo diabetu na stan sercevo-sudinnoï sistemi. Naukovij visnik Uzhgorods'kogo universitetu. Serija: Medicina.; 1: $168-177$.

23. Paneni F, L?scher TF. (2017) Cardiovascular Protection in the Treatment of Type 2 Diabetes: A Review of Clinical Trial Results Across Drug Classes. Am J Med.; 130(6S): S18-S29; Avogaro A, Fadini GP, Sesti G, Bonora E, Del Prato S. Continued efforts to translate diabetes cardiovascular outcome trials into clinical practice. Cardiovasc Diabetol. 2016; 15: 111

24. Brohall G, Oden A, Fagerberg B. (2006) Carotid artery intima-media thickness in patients with type 2 diabetes mellitus and impaired glucose tolerance: a systematic review. Diabet Med.; 23: 609-616.

25. Gomez-Marcos MA, Recio-Rodriguez JI, et al.( 2011) Yearly evolution of organ damage markers in diabetes or metabolic syndrome: data from the LOD-DIABETES study. Cardiovasc Diabetol.;10:90

26. Molecules. 2019 Jun; 24(11): 2062.doi: 10.3390/molecules24112062 The Multiple Faces of C-Reactive Protein-Physiological and Pathophysiological Implications in Cardiovascular Disease Magdalena Boncler, 1,* Yi Wu,2 and Cezary Watala1

27.C-reactive protein in atherosclerosis: (2006) Moniek P.M. deMaat; A causal factor Elaine Paffen, Author Notes Cardiovascular Research, Volume 71, Issue 1, July, Pages 30-39, https://doi.org/10.1016/ j.cardiores.2006.03.004

28. Steyers CM, Miller FJ (2014). Endothelial dysfunction in chronic inflammatory diseases. Int J Mol Sci; 15:11324-11349 [PMID: 24968272 DOI: 10.3390/ijms150711324

29. Szuszkiewicz-Garcia MM, Davidson JA. (2014) Cardiovascular disease in diabetes mellitus: risk factors and medical therapy. Endocrinol Metab Clin North Am; 43: 25-40 [PMID: 24582090 DOI: 10.1016/ j.ecl.2013.09.001

Received: 09-Sep-2020 Accepted: 08-Dec-2020 